\title{
Inconstitucionalidad por Omisión. Una Reforma Constitucional (referida a la Ley de Responsabilidad del Estado y de los Servidores Públicos)
}

\author{
Shirley Patricia Berrios \\ Profesora Investigadora, Instituto de Investigación Jurídica \\ Universidad Nacional Autónoma de Honduras
}

\section{RESUMEN}

El presente artículo analiza que se entiende por insconstitucionalidad por omisión y la facultad de los tribunales de establecer o determinar dicha figura, teniendo la prioridad el Poder Legislativo de emitir leyes, como ser la ley de Responsabilidad Civil del Estado y Responsabilidad Civil Solidaria, Penal y Administrativa de los Servidores del Estado, ya que todo mandato de la Constitución de la República, tiene que ser obligatoriamente cumplido, de lo contrario se estaría violentando el orden primario del Sistema Jurídico Nacional.

\section{ABSTRACT}

This Article analyzes what is understood by Unconstitutionality by Omission and the power of the courts to establish or determine this figure, by having the Legislative Power, the priority to issue laws, such as the Civil Liability Act of the State and Civil, Criminal and Administrative Solidary Liability, of Servants of the State, as a command of the Constitution, must compulsory be enforced, otherwise it would be violating the primary order of the National Legal System.
Palabras clave: Constitución, El Legislativo, Inconstitucionalidad por omisión, Estado
Keywords: Constitution, Legislative, Unconstitutionality by omission, State. 


\section{INTRODUCCIÓN}

El principio fundamental en que descansa el Derecho Constitucional es el de la supremacía de la Constitución, que consiste en el hecho de fungir como la norma jurídica superior, fundamental, primaria, que da validez y unidad a un sistema jurídico nacional; así la Constitución es la fuente última de validez de un ordenamiento, de tal suerte que para que una norma jurídica cualquiera sea válida, requiere encontrar su fundamento de validez, de conformidad con las respectivas normas jerárquicas superiores $y$, en última instancia, con la Constitución.

El Estado moderno evolucionó de un sistema absolutista en el que los administrados no tenían ninguna posibilidad de defensa frente a los designios y mandatos del poder público, no fue, sino hasta que con la Revolución Francesa y la incorporación al Estado de los principios de división de poderes y el principio de legalidad se puede afirmar surge un verdadero Estado de Derecho, entendido como aquel en el que se encuentran perfectamente acotadas y limitadas las facultades del poder público y garantizados los derechos de los gobernados.

En efecto, el principio de la división de poderes cuyo objetivo fundamental es impedir su ejercicio arbitrario del poder por parte de uno de ellos, constituye una forma para imponer límites al poder público, asimismo y como complemento del principio enunciado debe haber un sistema que garantice los derechos del individuo, de ahí que en el artículo 16 de la Declaración Universal de los Derechos del Hombre y del Ciudadano se mencione que aquella sociedad en la que se garantiza los derechos individuales, no estuviera asegurada, ni la separación de poderes establecida, no tendría Constitución.

Es cierto, por tanto, que el poder del Estado limita su actuación a los mandatos de la ley, principio de legalidad, la cual, si bien emana de uno de los poderes constituidos, el Legislativo, debe ser entendido como la expresión de la soberanía del pueblo, mediante la representación política ante el congreso o parlamento. Dentro de este orden de ideas, todo lo preceptuado en la constitución, tiene que ser obligatoriamente cumplido, de lo contrario estaríamos violentando el orden primario del sistema jurídico nacional. Bajo esa perspectiva, podríamos hablar de que puede existir un desacato al principio de supremacía constitucional que se origina de la oposición expresa de una norma con la Constitución, también 
cuando el Poder Legislativo no desarrolla a través de una ley los mandatos de la Constitución, esto es, no crea las normas jurídicas que requieren la efectividad de sus postulados, es otra forma de no dar cumplimiento al mandato constitucional.

En Honduras no hemos tomado en consideración la figura de "Inconstitucionalidad por Omisión", que existe en otras legislaciones de América Latina, por medio de la cual, se ha demandado la omisión del Congreso Nacional de emitir leyes que la Constitución de la República declara que deben de decretarse; tal hecho me motivó a investigar sobre lo que se entiende por la institución de inconstitucionalidad y específicamente en su carácter omitivo, tomando como referencia un caso específico como es el de haberse omitido la emisión de la Ley de Responsabilidad del Estado y de los Servidores Públicos y es así que incorporamos en el Plan Operativo Anual para el año 2009, una investigación documental referente al tema. La parte doctrinal se cubrió con las exposiciones de tratadistas latinoamericanos, el párrafo referente al Derecho Positivo, con el análisis de nuestra Constitución, Decreto No. 131 del 11 de enero de 1982, sus reformas e interpretaciones y la parte práctica mediante el estudio de casos reales de países Latinoamericanos.

En la actualidad considero de suma importancia tratar este asunto, por cuanto en los dos últimos años se ha cuestionado reiteradamente la positividad de nuestra Constitución al grado de proponer una Asamblea Nacional Constituyente para emitir una nueva Constitución, ya que la actual, a criterio de algunos, no cumple con los objetivos de un desarrollo social. La investigación no pretende cuestionar la positividad de la norma suprema, sino Ilamar la atención sobre un problema importante que es el hecho de que existen instituciones que no se han hecho efectivas por razones que desconocemos, como ser el caso de que no existe una Ley de Responsabilidad de los Funcionarios Públicos, normas que regulen el régimen financiero y económico con vista a un Estado de Bienestar, una Ley de Reforma Agraria, Ley de la Proveeduría General de la República, en fin una gran cantidad de regulaciones que la Constitución establece y que el Congreso Nacional ha omitido su emisión.

Presentamos a la comunidad nacional en general y a la comunidad universitaria en particular la investigación sobre el silencio de nuestros legisladores al no emitir leyes que son autorizadas por nuestra carta magna y específicamente la Ley de Responsabilidad del Estado y de los Servidores Públicos, ordenada en el Artículo 
327 de nuestra Constitución; esperamos que este documento sirva de base para alertar a nuestros legisladores y que en un futuro el Congreso Nacional decrete las normas que la Constitución ordena y evitar en un caso concreto, una demanda de "Inconstitucionalidad por Omisión".

\section{CAPÍTULO I}

\section{ANTECEDENTES HISTÓRICOS}

Para conocer nuestro sistema constitucional actual en donde se establece por medio del Artículo 327, la obligación del Estado de contar con una norma que regule la responsabilidad civil del Estado así como la responsabilidad civil, penal y administrativa de los servidores públicos, previamente se analizará las dos Constituciones que han precedido a la Constitución actual, es decir la Constitución de 1957 y la de 1965, a fin de conocer desde cuando el Estado ha tenido la preocupación por responder por los actos administrativos de este y de sus funcionarios públicos y se verá lo referente a la historia de la institución de la inconstitucionalidad por omisión.

"El empleo de "omisión" en sentido jurídico, parece tener su origen en el derecho romano, en el cual podemos detectar su uso en sentido privado y público, aunque en todo caso parece de poca relevancia. En la esfera de lo privado hacía referencia, por ejemplo, a aquellos casos en que el juez se abstenía de dictar sentencia, o a la figura de la preterición." (Fernández Rodríguez, 2007).

En efecto para "algunos autores, el termino por omisión se aludía al olvido del testador respecto al heredero legítimo, que ni es instituido heredero ni es excluido de la herencia. Tal olvido era la idea central de la preterición y tenía unas claras e importantes consecuencias, llegando incluso a provocar la nulidad del testamento. Con esto, sólo estamos refiriéndonos únicamente en el terreno del derecho privado sin conexión con las ideas que nos interesan, salvo la presencia de una obligación que somete al testador y cuya debilidad por un "dejar de hacer" tiene consecuencias jurídicas. En el campo del derecho público se emplea, por ejemplo, cuando un magistrado omite exigir una caución como la tutelar. Lo que sí se utiliza, aunque en muy pocas ocasiones, en un sentido que podríamos denominar Jurídico-Público, es el verbo "omitto", en donde se halla la raíz de "omissio-onis". De entre estos escasos usos cabe destacar que algunos de ellos 
hacen referencia a "neglegere". Aunque, insisto, los supuestos no tienen demasiada importancia. Además nos movemos en terreno de personas físicas, no de órganos.(Fernanadez, Rodríguez 2007).

Se considera que se tuvo primero en cuenta el sentido jurídico-penal de omisión y luego se desplazó al Derecho Constitucional, para referirse al tema a estudiar. En el Derecho Penal los delitos y las faltas pueden surgir de acciones como de omisiones que sean dolosos y culposos, siempre y cuando estén establecidas por la ley. La Constitución Política de 1957 regula en sus Artículos del 309 al 314 De la Responsabilidad y declara en su Artículo No. 310 "que los funcionarios y empleados públicos son responsables de sus actos"; y el 312 en donde se establece "que los funcionarios y empleados públicos que violaren cualquiera de los derechos y garantías consignadas en esa Constitución, serán responsables civil y criminalmente; no podrán obtener indulto ni conmuta en el período en curso ni en el siguiente".- No existe la declaración expresa de la emisión de una Ley que Regule la Responsabilidad del Estado y de sus Servidores.

La Constitución Política de 1965 en su Título X Responsabilidad en sus Artículos 315 al 318 expresan la responsabilidad del Estado y sus servidores públicos, específicamente el Artículo 317 establece: Los funcionarios y empleados públicos que violaren cualquiera de los derechos y garantías consignadas en esta constitución serán responsables civil y criminalmente; no podrán obtener indulto ni conmuta en el periodo en curso ni en el siguiente. En ambas Constituciones se encuentra la institución de la responsabilidad del servidor público pero en ninguna de ellas se establece plenamente la obligación del Congreso Nacional de contar con una Ley que regule tanto la responsabilidad del Servidor Público como del Estado; no fue hasta la Constitución de 1982 en donde expresamente la Asamblea Nacional Constituyente incorpora en el Artículo No. 327, que la Ley regulara la Responsabilidad Civil del Estado, así como la Responsabilidad Civil Solidaria, Penal y Administrativa de los Servidores del Estado.

\section{CAPÍTULO II}

\section{CONCEPTUALIZACIÓN}

Como un acercamiento del concepto de Inconstitucionalidad por Omisión, entendemos la inactividad del Poder Legislativo de emitir las leyes que la Constitución de la República autoriza. Examinando la expresión 
"Inconstitucionalidad por Omisión" vemos que por inconstitucionalidad entendemos como un acto o conducta que violenta los principios establecidos en la carta magna. La palabra omisión se refiere al hecho de omitir, incumplir, ignorar, no realizar, dejar de hacer algo que se está obligado a realizar.

En el Diccionario Enciclopédico de Derecho Usual de Guillermo Cabanellas, encontramos las siguientes definiciones: "Inconstitucionalidad. Quebrantamiento de la letra o del espíritu de la Constitución (V.) Por leyes del parlamento, por decretos-leyes o actos de gobierno. De acuerdo con la organización judicial de cada país, la inconstitucionalidad puede declararse, en lo relativo a las normas legales, por un juez cualquiera, como conflicto o en definitiva de leyes, o por un tribunal sui generis, el de mayor jerarquía y especial para estos casos, dada la índole peculiar de los preceptos constitucionales, texto que es como la ley de leyes." "Omisión.- Abstención de hacer; inactividad; quietud.- Dejación de decir o declarar; silencio; reserva; ocultación de lo que se sabe; negativa a declarar.- olvido de deberes, mandato u órdenes.- Descuido, falta a las obligaciones.- Lenidad, negligencia, flojedad."(Cabanellas, 1989)

El jurista peruano, Gerardo Eto Cruz señala..." que la inconstitucionalidad por omisión, es la que resulta por el silencio o la inercia de cualquier órgano de poder, el cual deja de hacer o practicar un mandamiento expreso por la Constitución en un tiempo razonable, ocasionado por el perjuicio, expandiendo un efecto dañino a todas las personas que podrán invocar a su favor la norma constitucional aun no reglamentada por el legislador." (Quispe Correa,2006)

También puede hablarse de omisión legislativa inconstitucional cuando el legislador no cumple con las órdenes de Legislar, esto es, aquellos mandatos al legislador que se traducen en una exigencia de legislar única y concreta, mediante la cual, por lo general, se ordena normativamente una institución. (Avalos, 2006).

El Profesor José Julio Fernández Rodríguez, Profesor de Derecho Constitucional de la Universidad de Santiago de Compostela, España, declara: por lo que respecta al vocablo "inconstitucionalidad", "No resulta problemático el uso que hacemos de él ya que estamos haciendo referencia a una conducta vulneradora de la carta magna. Estas vulneraciones tienen diversas causas y se presentan con matices diferentes. Asimismo, las consecuencias de tales infracciones pueden ser distintas. Pero todas ellas suponen un ataque a los preceptos básicos del ordenamiento 
jurídico y una agresión a los valores vitales emanados de las decisiones políticas fundamentales recogidas en el texto constitucional".

Mucho más problemático nos resulta el vocablo "omisión", que alude a una inactividad, a una inacción, a un dejar de hacer o de decir algo. El español Silvela (referido por Fernández) afirmaba a principios del siglo XX que la omisión era la "inactividad de la voluntad que deja de traducir la idea de la ley en hechos reales". De esta forma, entendía la omisión como la no realización de la ley, a diferencia de la acción que era la realización de la voluntad del sujeto actuante. La doctrina penal ha considerado que la omisión relevante para esta rama del derecho posee una naturaleza normativa y no pre-jurídico, es decir, la omisión que origina la reacción del ordenamiento penal es la omisión del actuar a que obliga la ley. La existencia de un deber de hacer proveniente de una norma es, por tanto, imprescindible. Este deber de hacer que impone la norma encuentra su razón de ser en la defensa de determinado bien jurídico digno de protección. En los delitos de omisión, el peligro para el bien jurídico existe previamente y es, precisamente, ese peligro previo el que origina, en el seno del ordenamiento jurídico, la espera de una conducta que lo conjure.

Se entiende "que esta idea de omisión penal fue la que se trasladó al seno del derecho constitucional para denominar a la institución que estamos tratando. La expresión penal tiene acuñada una carga de anti juridicidad y de reprochabilidad que está forzosamente presente en una inactividad inconstitucional. El trasfondo, haciendo quizá una simplificación excesiva, es el mismo, vulneración del ordenamiento jurídico a causa de un dejar de hacer por parte de quien está obligado a actuar, obligación que tiene su origen en una norma vigente en el momento de acontecer la infracción. Pese a ello, no cabe duda que el derecho penal y la omisión penal se dirigen a personas físicas, únicas que pueden ser sujetos pasivos de la responsabilidad criminal. Por el contrario, el que incurre en inconstitucionalidad por omisión es, en principio, el Poder Legislativo, dejando ahora al margen las responsabilidades del Ejecutivo." (Fernández, 2007).

Según los estudiosos de este tema las palabras inactividad o dejación tal vez hubiera sido más competente para el Derecho Constitucional al estar asignado de una generalidad de transferir a los poderes públicos, se sigue utilizando dicha palabra porque ahora es la conocida en distintas lenguas. Tanto por razones de orden técnico, como por razones de orden fáctico, el texto de las constituciones 
no agota las materias que regula. La obra del constituyente queda, en algunos aspectos, incompleta. Como consecuencia de este hecho, la propia Constitución establece encargos u obligaciones concretas, dirigidas generalmente al legislador ordinario, para que complete la voluntad del constituyente.

En ocasiones, esos mandatos imperativos de la Constitución, bien sean de carácter legislativo o de otra especie, no se cumplen, perjudicando así la fuerza normativa de la Constitución y produciéndose un verdadero fraude constitucional. Estamos, entonces, frente al caso de Inconstitucionalidad por Omisión, en donde por la desidia, inercia, quiescencia o inacción de los poderes constituidos, se deja sin aplicación práctica lo preceptuado por la norma constitucional. Si nos preguntamos si la inconstitucionalidad por omisión es inocua, la respuesta es definitivamente negativa, porque el silencio del legislador o de la autoridad frente al cumplimiento de un mandato constitucional, es una manera de hacer política que, indudablemente, trae aparejadas consecuencias sociales y jurídicas, pues permite la supervivencia del estatus quo e impide el cambio que la norma constitucional persigue.(Castro Patino,2003)

Continua manifestando el tratadista del tema..."No podemos permitir que se convierta la Constitución en un texto lisiado, imposibilitado de caminar, porque le falta una ley que en algunos aspectos desarrolle sus mandatos. Declarar la inconstitucionalidad de normas de inferior rango que contradigan el texto constitucional, así como buscar la plena operatividad de las normas constitucionales, aun cuando la inacción legislativa haya frustrado la expedición de la ley reglamentaria, forman parte consustancial de la defensa jurídica de la Constitución". En el primer caso, cuando se expide una ley que transgrede la Constitución, estamos frente a una violación constitucional de carácter positivo. En el segundo, cuando se incumple con la expedición de una ley o la ejecución de un acto ordenado por la Constitución, estamos en el ámbito de la violación constitucional de carácter negativo, porque es justamente la quiescencia, la inacción u omisión de la obligación constitucional, la que produce el vicio.

Para el primero de los casos anteriormente señalados, esto es, para la violación constitucional de carácter positivo, existe la acción de inconstitucionalidad consagrada en nuestra carta magna. Para el segundo caso, esto es, la omisión inconstitucional o violación de carácter negativo, salvo los casos de omisiones administrativas que impliquen violación de un derecho subjetivo, que causen o puedan causar un daño inminente o grave, tutelado por la acción de amparo, no 
existe en nuestro texto constitucional disposiciones que prevengan, corrijan o sancionen la omisión inconstitucional en el dictado de normas u omisiones administrativas con efectos generales. (Castro Patino, 2003).

\section{CAPÍTULO III}

\section{ANÁLISIS DEL ARTÍCULO 327 DEL DECRETO NO. 131 DEL 11 DE ENERO DE 1982.}

Para analizar el Artículo 327 de la Constitución vigente es necesario referirse a todo el Capítulo XIII del Título V De la Responsabilidad del Estado y sus Servidores de los Artículos 321 al 327.

En primer lugar cabe hacer una reflexión sobre este Capítulo por cuanto viene a constituir dentro del sistema constitucional una definición formal hacia el Estado de Derecho por cuanto consideramos que un Estado es de Derecho cuando cumple con tres requisitos: un sistema de normas que otorguen derechos y establezcan obligaciones a los ciudadanos, un sistema judicial que proteja la norma sustantiva contentiva de los derechos subjetivos de los administrados y un sistema de responsabilidad del Estado y de los servidores públicos que reparen los daños causados a los particulares por la emisión de resoluciones administrativas violatorias a las leyes.

Nuestra Constitución no solo es una simple norma, sino que es la primera norma del ordenamiento jurídico nacional, la norma fundamental, "lex superior" por cuanto la Constitución define las fuentes formales del derecho, de modo que solo podrán dictarse normas conforme a lo dispuesto en la Constitución, por tanto es la primera norma de producción, la "norma normarum", es la fuente de fuentes del Derecho; en segundo lugar porque en la medida en que la Constitución es la expresión de una intención fundacional, configuradora de un sistema jurídico que ella determine, en esa misma intensidad será la obligación de elaborar la norma secundaria que cumplimente dicha intención; en este caso la responsabilidad del Estado y del Servidor Público.

El Artículo No. 321 señala que los servidores del Estado no tienen más facultades que los que expresamente les confiere la ley, todo acto que ejecuten fuera de la ley es nulo e implica responsabilidad, constituye este Artículo el principio de 
legalidad, en donde garantiza a los ciudadanos que tendrán seguridad jurídica, ya que ninguna autoridad podrá emitir actos administrativos que estén en contra de la ley, y que sucede cuando un órgano emite una resolución que afecte un derecho subjetivo o un interés legítimo.- En este caso el particular lesionado en sus derechos e intereses legítimos tiene la posibilidad de recurrir ante la misma autoridad administrativa en la interposición de los recursos establecidos; y si aun persiste la violación a los derechos del recurrente, este tiene la facultad de interponer en el término legal una demanda ante la jurisdicción contenciosa administrativa a fin de que esta anule el acto administrativo demandado y sea indemnizado por los daños y perjuicios ocasionados.

Cientos de casos se han ventilado ante los Juzgados y Tribunales de lo Contencioso Administrativo y en la mayoría de los casos el Estado ha sido condenado a anular la resolución administrativa violatoria a la ley y pagar los daños y perjuicios ocasionados al administrado.- El Estado paga las cantidades por las que ha sido condenado en virtud de lo establecido en el Artículo No. 324 que establece que si el servidor público infringe la ley en perjuicio de particulares será civil y solidariamente responsable junto con el Estado o con la institución estatal a cuyo servicio se encuentre, sin perjuicio de la acción de repetición de estos pueden ejercitar contra el servidor responsable, en los casos de culpa o dolo.Hasta la fecha no conozco ningún caso en que el Estado haya ejercido la acción de repetición contra un funcionario público responsable por la emisión de un acto administrativo violatorio a la ley, considero que esto es debido a que no existe una Ley de Responsabilidad del Estado y del Servidor Público como lo establece el Artículo No. 327 de la Constitución.

El Artículo No. 327 constitucional establece expresamente: “La Ley regulará la Responsabilidad Civil del Estado, así como la Responsabilidad Civil Solidaria, Penal y Administrativa de los Servidores del Estado." El Artículo anteriormente señalado establece claramente el hecho de que deberá de emitirse una ley la cual va a regular en primer lugar la responsabilidad civil del Estado, solo civil, porque el Estado como una persona moral no puede delinquir y porque en la función administrativa, y siguiendo la teoría del Órgano, la persona que actúa por el órgano lo hace como tal; la misma ley contendrá disposiciones que vengan a determinar la existencia de responsabilidad civil, juntamente solidaria con el Estado, y la responsabilidad individual penal y administrativa que como funcionario se haya hecho acreedor por los actos administrativos violatorios a la 
ley. ¿Qué sucede entonces al no haber una ley de responsabilidad como la antes nominada? Considero que no se podrá, en determinados casos, tener una verdadera seguridad jurídica al no poder demandar al Estado y obtener la indemnización que establece la Ley de la Jurisdicción de lo Contencioso Administrativo, teniendo en este caso que interponer un recurso de inconstitucional por omisión, así como también no se puede ejercer la acción de repetición contra el funcionario violatorio de la ley, no pudiendo establecer la obligación del funcionario y tener que pagar las indemnizaciones solamente por el Estado; existiendo entonces dentro de la Administración Pública funcionarios violadores de la ley. Hasta la fecha no ha habido necesidad de interponer un recurso de inconstitucionalidad por omisión en virtud de que el Estado ha asumido la responsabilidad de pago de las indemnizaciones a que ha sido condenado.

\section{CAPÍTULO IV}

\section{ANÁLISIS DE NUESTRO SISTEMA LEGAL}

Únicamente la Corte Suprema de Justicia, por medio de la Sala de lo Constitucional, como intérprete último y definido en la Constitución en los casos concretos sometidos a su conocimiento, tiene la facultad originaria y exclusiva para conocer de la garantía de inconstitucionalidad y conforme lo establecido por la Constitución, la anterior posición se encuentra establecido en el Artículo No. 74 de la Ley sobre Justicia Constitucional, Decreto 244-2003.

La Constitución de la República establece en su Artículo No. 184 que las leyes podrán ser declaradas inconstitucionales por razón de forma o de contenido.- A la Corte Suprema de Justicia le compete el conocimiento y la resolución originaria y exclusiva en la materia, y deberá pronunciarse con los requisitos de las sentencias definitivas. La declaración de inconstitucionalidad de una ley y su inaplicabilidad, podrá solicitarse, por quien se considere lesionado en su interés directo, personal y legítimo, señala el Artículo No. 185.- Dicho Recurso de Inconstitucionalidad se interpondrá ante la Corte Suprema de Justicia y la ley reglamentará los casos y la forma de revisión, establece el Artículo No.186. Asimismo el Artículo No. 313 establece las atribuciones de la Corte Suprema de Justicia y específicamente en su numeral 5 señala: conocer de los recursos de casación, amparo, revisión e inconstitucionalidad de conformidad con esta Constitución y la Ley y el Artículo 
No. 316 declara que en la Corte Suprema de Justicia habrá una Sala de lo Constitucional que conocerá de los Recursos de Inconstitucionalidad.

Como se desprende de lo anteriormente mencionado, tenemos todo un sistema jurídico para presentar recursos de inconstitucionalidad, pero en ninguno de los artículos mencionados establece expresamente la facultad que tiene la Corte Suprema de Justicia a través de la Sala de lo Constitucional de conocer de Recursos de Inconstitucionalidad por Omisión Legislativa, es más cuando revisamos el Capítulo III De las Sentencias en los Procedimientos de Inconstitucionalidad del Título III del Control de Constitucionalidad de la Ley Sobre Justicia Constitucional, se encontró que el Artículo No. 89 señala que la sentencia podrá declarar la inconstitucionalidad total o parcial de una ley.- El Artículo No. 94 del mismo cuerpo legal declara que la sentencia en que se declare la inconstitucionalidad de una norma será de ejecución inmediata, y tendrá efectos generales y por tanto derogará la norma inconstitucional, debiendo comunicarse al Congreso Nacional, quien lo hará publicar en el Diario Oficial La Gaceta.

Con estos dos Artículos anteriormente mencionados se viene a confirmar que nuestro sistema no cuenta con la garantía constitucional del Recurso de Inconstitucionalidad por Omisión. No nos queda más que para ejemplificar la investigación documental, hacer acopio del derecho comparado y presentar como consideran esta garantía constitucional, la legislación de otros Estados. La Corte Suprema de Justicia de la República de El Salvador ha resuelto favorablemente, admitiendo un recurso de esa clase, en el que se alega que los trabajadores permanentes de la empresa privada o de aquellas instituciones oficiales autónomas o semiautónomas donde se aplica el Código de Trabajo, puedan renunciar a su trabajo voluntariamente; y, recibir la prestación económica que hasta el día de hoy es exclusivo para aquellos trabajadores que son despedidos sin justificación alguna por el patrono.

Con esta resolución de la Corte Suprema de Justicia Salvadoreña se pone fin a una larga tradición de acoso patronal, mediante el cual obligaban a ciertos empleados a renunciar "voluntariamente" para así negarles las prestaciones correspondientes (Indemnización económica). Esto ocurría porque el legislador nunca estableció las reglas para hacer efectivo este derecho, que desde el año 1983 existe en la Constitución de la República, en el Art. No. 38 numeral 12. Por el momento solamente se está a la espera del informe que al respecto, brinde la Asamblea 
Legislativa, ya que así ha sido requerido por la Corte Suprema de Justicia, por ser parte del procedimiento que establece la Ley de Procedimientos Constitucionales. Es oportuno aclarar que este recurso había sido intentado en varias ocasiones, siendo rechazado por los anteriores integrantes de la Sala de lo Constitucional de la Corte Suprema de Justicia.

RESOLUCIÓN: AL ABOGADO JUAN RAMÓN ARAUJO LÓPEZ HAGO SABER: Que en el proceso de Inconstitucionalidad número 53-2009, promovido a fin de que se declare la Inconstitucionalidad por Omisión, en tanto que no se ha desarrollado la regulación prevista en el Art. 38 ord. $12^{\circ}$ de la Constitución; La Sala de lo Constitucional de la Corte Suprema de Justicia ha pronunciado la RESOLUCIÓN que literalmente DICE:

Sala de lo Constitucional de la Corte Suprema de Justicia, San Salvador a las doce horas del día diecinueve de febrero. Analizada la demanda presentada por el ciudadano Juan Ramón Araujo López, mediante la cual solícita se declare la inconstitucionalidad por omisión, en tanto que no se ha desarrollado la regulación prevista en el art. 38 ord. $12^{\circ}$ de la Constitución; se hacen las siguientes consideraciones:

1. El pretensor alega que en el art. 38 ord. $12^{\circ} \mathrm{Cn}$. existen dos figuras jurídicas laborales: (i) la renuncia voluntaria a un puesto de trabajo permanente y (ii) la indemnización que pagará el patrón al trabajador permanente en caso de darse la renuncia voluntaria.

Asimismo, manifiesta que los aspectos sobre los cuales debió legislarse en el Código de Trabajo son: (i) la prestación económica por renuncia voluntaria; (ii) la forma de computarse la referida prestación económica por renuncia ante cualquier entidad donde dicho cuerpo legal sea aplicable --según lo regulado por el art. 1 del Código de Trabajo-; y (iii) la renuncia voluntaria del trabajador permanente de aquellas empresas, instituciones oficiales autónomas o semiautónomas donde se aplique el Código de Trabajo como norma secundaria reguladora de las relaciones laborales. El art. 54 del Código de Trabajo - continúa - regula las causales de terminación de contrato por mutuo consentimiento y por renuncia pero omite legislar sobre el caso específico de renuncia voluntaria y la prestación económica, así como la manera de computar el monto a pagar en caso de verificarse la renuncia voluntaria, razón por la cual 
existe una omisión absoluta del legislador al no regular estos supuestos.

2. Sobre este tipo de argumentos es pertinente señalar que la inconstitucionalidad por omisión no se encuentra regulada en la L. Pr Cn., sin embargo, este Tribunal ha considerado que tal mecanismo es aplicable en nuestro sistema de defensa de la Constitución.

De acuerdo con la Sentencia de 28-IV-2000, pronunciada por en el proceso de Inc. 2- 95, los mandatos constitucionales sobre los cuales puede verificarse la omisión no necesariamente deben aparecer explícitos en el texto de la Constitución escrita, sino que también pueden ser derivados por la jurisprudencia constitucional; asimismo, tampoco es imprescindible que los mandatos contengan un plazo para la emisión de tales disposiciones infra constitucionales, pues esta misma Sala puede determinar la razonabilidad de la dilación en el comportamiento omisivo de los órganos y entes investidos de potestades normativas.

Por consiguiente, los aspectos vinculados a la vulneración por omisión de los mandatos constitucionales son: (i) la existencia del mismo en el texto constitucional —el asunto de "si existe" el mandato constitucional-; y (ii) la razonabilidad del tiempo transcurrido para cumplir con la emisión de disposiciones infra constitucionales —el "cuándo" se debe dar cumplimiento al mandato constitucional. Las anteriores razones justifican que este tribunal conozca y decida sobre aquellos comportamientos omisivos de los entes investidos de potestades normativas, en cuanto a la producción de disposiciones infra constitucionales que desarrollen las normas que contienen mandatos constitucionales, cuando la dilación irrazonable en la emisión de las primeras provoque la ineficacia de las segundas.

II Con base en lo expuesto, normativa y jurisprudencia constitucional citada y en virtud de los artículos 6 y 7 de la Ley de Procedimientos Constitucionales, esta Sala.

RESUELVE:

1. Admítase la demanda presentada el ciudadano Juan Ramón Araujo López, mediante la cual solicita se declare la inconstitucionalidad por omisión, en tanto que no se ha desarrollado la regulación prevista en el art 38 ord. $12^{\circ}$ de la 
Constitución. La anterior admisión deberá circunscribirse al análisis de la falta de regulación de la compensación económica al trabajador cuando exista renuncia voluntaria al puesto de trabajo.

2. Rinda informe la Asamblea Legislativa, de conformidad al art. 7 de la L. Pr. Cn., en el plazo de diez días hábiles contados a partir de la notificación de la presente resolución, mediante el cual justifique la omisión aludida en relación con los motivos esgrimidos por el demandante.

3. Tome nota la Secretaria de este tribunal del lugar señalado por la parte actora para recibir los actos procesales de comunicación.

4. Notifíquese.

\section{CONCLUSIONES}

Habiendo obtenido y analizado la información relacionada con la inconstitucionalidad por omisión, procedo a presentar las conclusiones siguientes:

1. La principal función de las Constituciones modernas consiste, de modo fundamental, en regular las relaciones entre el poder público y los gobernados a través del establecimiento de un catálogo de garantías individuales, y en limitar el campo de acción del primero para salvaguardar las segundas.

2. La Constitución como norma fundamental y base del orden jurídico que rige un Estado, no debe ser estática, sino que como cualquier otra disposición de observancia general, requiere adecuarse a nuestra realidad socio política, por lo cual exige la implementación de un sistema que permita su modificación.

3. Por Inconstitucionalidad por Omisión, entendemos la inactividad del Poder Legislativo de emitir las leyes que la Constitución de la República autoriza.

4. En nuestra Constitución existen preceptos que ordenan la emisión de leyes que hasta la fecha no se han emitido como ser: La Ley de Responsabilidad Civil del Estado y Responsabilidad Civil Solidaria, Penal y Administrativa de los Servidores del Estado, tal como lo ordena el artículo 327 de la Constitución de la República.

5. La Constitución se ha convertido en un texto lisiado por la falta de leyes en algunos aspectos desarrolle sus mandatos.

*Tomado de la página web: www.plazalegal.blogspost.com/2010/03/sala-de-constitucional. 
6. En todo nuestro sistema jurídico no existe una referencia al Principio de Inconstitucionalidad por Omisión Legislativa.

7. Se recomienda una reforma constitucional a fin de incorporar la figura de la Inconstitucionalidad por Omisión Legislativa e incorporar la normativa correspondiente a la Ley Sobre Justicia Constitucional.

\section{BIBLIOGRAFÍA}

(n.d). Retrieved 2010, 21-junio from Plaza Legal: www.plazalegal.blogspost.com/2010/03/sala-de-constitucional

Avalos Díaz, S.V. (2006). Inconstitucionalidad por Omisión Legislativa, su Tutela en el Derecho Mexicano. Retrieved 2010, 25-mayo from www.scin.gob.mx/.../pdf/lic-Sofía-Verónica-Avalos-Díaz.pdf

Cabanellas, G. (1989). Diccionario Enciclopédico de Derecho Usual. Buenos Aires, República Argentina: Editorial Heliasta S.R.L.

Castro Patino, I. (2003). La Inconstitucionalidad por Omisión. Retrieved 2010, 14junio from Revista Jurídica:

www.revistajuridicaonline.com/index.php

Fernández Rodríguez, J. J. (2007 07-mayo). Aproximación al Concepto de Inconstitucionalidad por Omisión. Retrieved 2010 16-junio from Biblioteca Jurídica Virtual del Instituto de Investigación Jurídicas, UNAM: www.juridicad.unam.mx

García de Enterria, Eduardo. Fernández Tomas, Ramón. "Curso de Derecho Administrativo I". Editorial Civitas, S.A. Madrid, 1984.

Quispe Correa, A. (2006). Inconstitucionalidad por Omisión. Retrieved 201021 mayo from Estudios constitucionales, año 4 No. 1, ISSN0718-0195, Chile, 2006:

www.cecoch.cl/docs/pdf/revistaaño41/revistaaño413.pdf

\section{Legislación}

1. Constitución de la República, Editorial OIM, 2009.

2. Ley Sobre Justicia Constitucional, Editorial OIM, 2009. 